\title{
Revisão Sistemática do Programa Intensivo de Fisioterapia Utilizando a Vestimenta com Cordas Elásticas
}

\author{
Sistematic Review of The Intensive Suit Therapy \\ Cristina Mattos Pereira Frange ${ }^{1}$, Thais de Oliveira Tarabal Silva ${ }^{2}$, \\ Sandra Filgueiras ${ }^{3}$
}

\section{RESUMO}

Introduçáo. Um novo programa intensivo de fisioterapia que utiliza uma veste ortótica vem se despontando no mercado internacional como um recurso promissor na reabilitação de pacientes neurológicos. No entanto, faz-se necessária a sistematização das evidências disponíveis sobre os efeitos da roupa com elásticos em um programa intensivo de fisioterapia para pacientes neurológicos. Objetivo. Determinar se o programa intensivo de fisioterapia utilizando a roupa com elásticos produz desfechos benéficos para indivíduos com déficits neurológicos. Método. Foi realizada uma pesquisa bibliográfica nas bases de dados Medline, PEDro, Lilacs e Scielo, sem restrição de data, nas línguas português, inglês e espanhol, por trabalhos que documentassem o uso do recurso e da vestimenta. Dados foram extraídos de forma padronizada de cada estudo. Resultados. 11 estudos, sendo 4 revisóes, 6 ensaios clínicos e 1 estudo de caso foram revisados. Apesar da diversidade dos protocolos, das características de participantes e dos instrumentos utilizados terem impedido o agrupamento dos resultados, a síntese em níveis de evidência demonstrou que a eficácia da técnica ainda não é comprovada. Consideraçóes finais. Os resultados desta revisão não fornecem suficiente evidência para embasar a prática clínica, havendo necessidade de mais estudos focando o recurso da roupa com elásticos em um programa intensivo de fisioterapia.

Unitermos. Fisioterapia, Neurologia, Desempenho Funcional, Aprendizagem Motora, Neuroplasticidade, Modalidades de Fisioterapia.

Citação. Frange CMP, Silva TOT, Filgueiras S. Revisão Sistemática do Programa Intensivo de Fisioterapia Utilizando a Vestimenta com Cordas Elásticas.

\begin{abstract}
Introduction. It is necessary to review the evidence in current literature to support the use of the suit therapy and the intensive suit therapy in neurological patients. Objective. To determine if the suit therapy and the intensive suit therapy produces benefic outcomes in patients with neurological disturbances. Method. Our search included Medline, PEDro, Lilacs and Scielo, with no restrictions of date, in english, portuguese or spanish languages. Results. 11 studies: 4 reviews, 6 clinical trials and 1 case study were reviewed. Despite the protocols variety, participant and instruments characteristics utilized made difficult to group and to analyze the results, having no evidence in literature. Conclusion. The results of this review do not provide sufficient evidence on which to base clinical practice. There is a need for studies to address these issues.
\end{abstract}

Keywords. Physical Therapy, Neurology, Functional Perfomance, Motor Apprenticeship, Neuroplasticity, Physical Therapy Modalities.

Citation. Frange CMP, Silva TOT, Filgueiras S. Sistematic Review of The Intensive Suit Therapy.
Pesquisa realizada na Faculdade de Ciências Médicas de Minas Gerais (FCMMG), Belo Horizonte, MG, Brasil.

1.Fisioterapeuta, especialista em Fisioterapia Neurológica pela FCMMG, Belo Horizonte-MG, Brasil.

2.Fisioterapeuta, mestre; docente e coordenadora de cursos na graduação e pós-graduaçáo em Fisioterapia da FCMMG, Belo Horizonte-MG, Brasil.

3.Fisioterapeuta, mestre; docente da FCMMG e PUC/BH, Belo Horizonte-MG, Brasil.
Endereço para correspondência: Cristina M P Frange Rua Aleixo Garcia, 51, apto.61 CEP 04545-010 - São Paulo, SP, Brasil E-mail: cristina.frange@uol.com.br 


\section{INTRODUÇÃO}

Novos métodos de reaprendizagem do controle motor, da postura e do equilíbrio em disfunções neurológicas e sensoriais despertam interesse para os profissionais da área de saúde. Há uma necessidade crescente de pesquisas na área de reabilitação, independentemente da idade e da doença. Os pacientes com disfunção neuromotora necessitam recuperar sua independência funcional, o que torna a reabilitação um processo complexo, exigindo a reconquista de muitas capacidades como o ganho de força muscular, a estabilidade, o controle motor, a restauração do controle postural e o máximo possível de mobilidade independente ${ }^{1}$.

Recentemente, um programa intensivo de fisioterapia (PIF) utilizando uma veste ortótica vem se despontando no mercado internacional como uma das promissoras técnicas de reabilitação para pacientes neurológicos. Esta órtese dinâmica é uma influência da pesquisa russa sobre o uniforme de cosmonautas que, em longas viagens ao espaço, sofriam com perdas de massa óssea e muscular, oriundas da ausência da gravidade $e^{2-4}$.

No início da década de 70, no século XX, a roupa Pinguin ou Penguin Suit atuava como um paliativo às condiçóes espaciais, sendo utilizada durante toda a jornada de trabalho. Adicionalmente, o aparato era utilizado para a realização de exercícios, simulando efeitos gravitários através de seus elásticos, enquanto os cosmonautas estavam no espaço ${ }^{5,6}$. A partir desta época, a roupa com elásticos e seus efeitos começaram a ser estudados e receberam diferentes nomes e "patentes" no mundo, com pequenas modificaçôes e adaptaçóes, porém com o mesmo princípio. Em 1991, na Polônia, foi lançado o AdeliSuit ou PolishSuit ${ }^{4}$. No início dos anos 2000 foram lançados o TheraSuit ${ }^{7}$ no Michigan (EUA) e o PediaSuit na Flórida (EUA); em 2005, o NeuroSuit na Geórgia (EUA). Hoje, existem clínicas de fisioterapia em todo o mundo que trabalham com este recurso.
Considerando que o PIF é um recurso de tratamento ainda novo e pouco estudado, porém cada vez mais disponível aos pacientes, esta revisão sistemática de literatura teve como objetivo determinar se o PIF utilizando a roupa com elásticos produz desfechos benéficos para indivíduos com déficits neurológicos, além de enfocar os efeitos da roupa com elásticos em si no processo de reabilitação.

\section{MÉTODO}

\section{Amostra}

As bases eletrônicas MedLine, PEDro, Lilacs e Scielo foram consultadas retrospectivamente, sem restrição de data, nas línguas português, inglês e espanhol, usando os seguintes descritores: TheraSuit, Suit Therapy, Adeli Suit, Pinguin Suit, Penguin Suit, PediaSuit, NeuroSuit e PolishSuit.

\section{Procedimento}

Os artigos foram selecionados por dois pesquisadores e obedeceram ao seguinte critério de inclusão: ter sido publicado nas línguas inglesa, portuguesa ou espanhola e abordar a técnica como um recurso de reabilitação fisioterapêutica.

Vinte e dois trabalhos foram pré-selecionados pelo conteúdo do título. Após a leitura dos resumos, 11 foram excluídos por não atenderem aos critérios de inclusão: 8 por estarem na língua russa, 2 por se tratarem de técnicas médicas (e não fisioterapêuticas) e 1 por ser comentário. Assim, 11 estudos foram incluídos para a etapa de análise crítica (Figura 1).

\section{RESULTADOS}

As características dos 11 estudos incluídos nesta revisão são apresentadas nos Quadros $1 \mathrm{~A}$ - $1 \mathrm{E}$ (ensaios clínicos e estudo de caso) e 2 (revisão de literatura). As revisões de literatura não foram incluídas na análise a seguir por serem revisóes narrativas. 


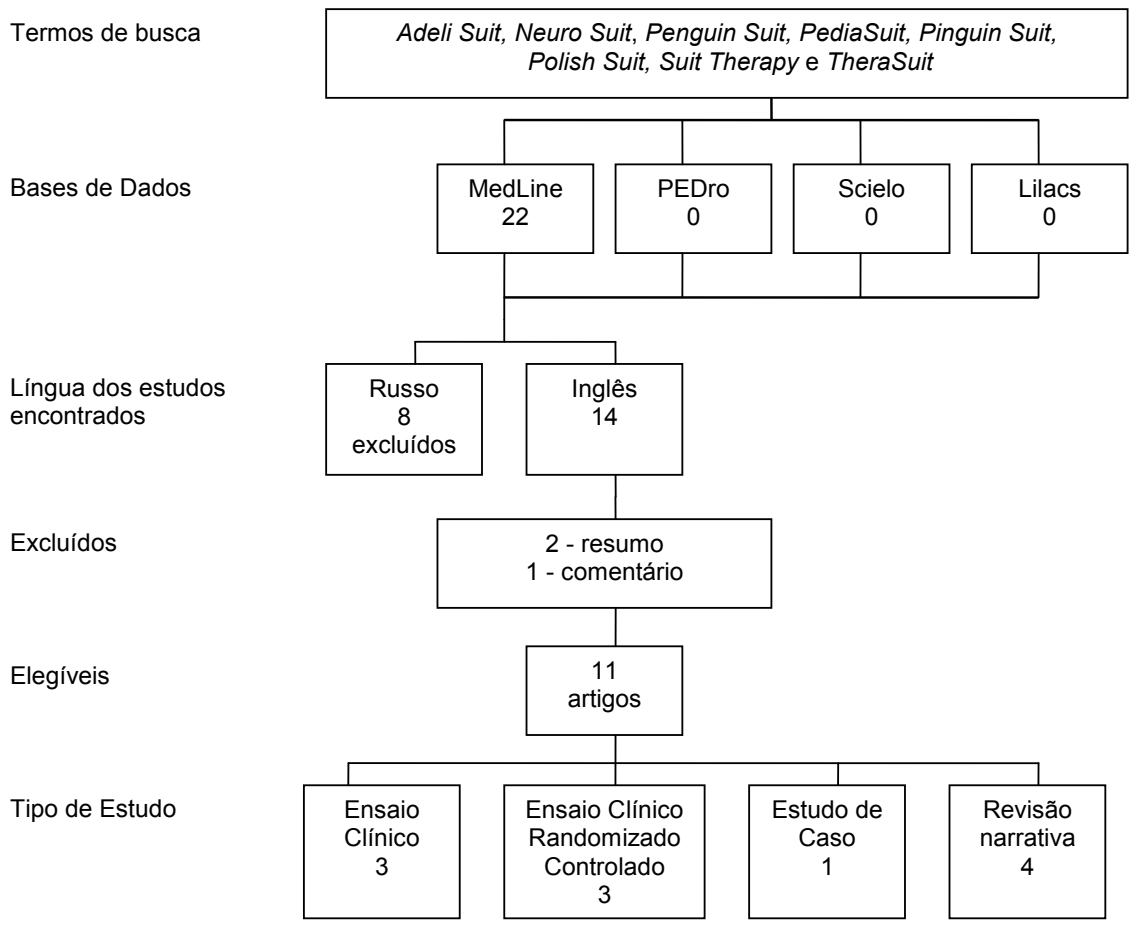

Figura 1. Fluxograma da seleção dos artigos incluídos na presente revisão.

\begin{tabular}{|c|c|c|c|c|c|c|}
\hline \multicolumn{7}{|c|}{ QUADRO 1A - Descriçáo dos estudos (ensaios clínicos e estudo de caso) selecionados } \\
\hline Estudo & $\begin{array}{c}\text { Desenho } \\
\text { Métodológico }\end{array}$ & Amostra & Desfechos Avaliados & $\begin{array}{c}\text { Instrumentos de } \\
\text { Avaliaçáo }\end{array}$ & $\begin{array}{c}\text { Análise } \\
\text { Estatística }\end{array}$ & $\begin{array}{c}\text { Efeitos Encontrados } \\
\text { (enumerados de acordo com os } \\
\text { desfechos avaliados) }\end{array}$ \\
\hline $\begin{array}{c}1997 \\
\text { Semeno- } \\
\text { va } \mathrm{KA}^{2}\end{array}$ & $\mathrm{EC}$ & $\begin{array}{l}94 \text { crianças } \\
\text { diplégicas }\end{array}$ & Não deixa claro & $\begin{array}{l}\text { Não deixa claro } \\
\text { Eletroencefalograma } \\
\text { (EEG) }\end{array}$ & $\begin{array}{c}\text { Não } \\
\text { especifica }\end{array}$ & $\begin{array}{l}\text { - reduçáo do tônus muscular } \\
\text { - melhora da habilidade de realizar } \\
\text { movimentos voluntários com as mãos } \\
\text { - melhora da disartria } \\
\text { - reduçáo da atividade patológica } \\
\text { subcortical }\end{array}$ \\
\hline $\begin{array}{l}1997 \\
\text { Shvarkov } \\
\text { SB et al. }{ }^{7}\end{array}$ & $\begin{array}{l}\text { EC } \\
\text { Follow-up } \\
\text { ( } 6^{\circ} \text { ao } 18^{\circ} \\
\text { mês })\end{array}$ & $\begin{array}{l}55 \text { adultos } \\
\text { lesão cérebro- } \\
\text {-vascular agu- } \\
\text { da, síndromes } \\
\text { hipercinéticas }\end{array}$ & $\begin{array}{l}\text { 1. distúrbios motores } \\
\text { 2. efeitos terapêuticos do } \\
\text { Adeli Suit } \\
\text { 3. força muscular } \\
\text { 4. espasticidade } \\
\text { 5. humor e bem estar } \\
\text { 6. auto cuidado } \\
\text { 7. severidade de síndromes } \\
\text { piramidais } \\
\text { 8. ansiedade } \\
\text { 9. atividade bioelétrica } \\
\text { cerebral } \\
\text { 10. amplitude do potencial } \\
\text { somatossensorial e visual }\end{array}$ & $\begin{array}{l}\text { Monitoração } \\
\text { Questionário } \\
\text { Testes psicológicos } \\
\text { Mensuração de força } \\
\text { muscular } \\
\text { Mensuração da } \\
\text { espasticidade } \\
\text { EEG } \\
\text { Potencial evocado } \\
\text { (não deixa claro quais } \\
\text { instrumentos foram } \\
\text { utilizados) }\end{array}$ & $\begin{array}{c}\text { Não } \\
\text { especifica }\end{array}$ & $\begin{array}{l}\text { 1. não menciona } \\
\text { 2. não menciona } \\
\text { 3. aumento em membros } \\
\text { paralisados } \\
\text { 4. redução } \\
\text { 5. melhora nas atividades, nos } \\
\text { cuidados próprios, no humor e bem estar } \\
\text { 6. capazes } \\
\text { 7. redução de } 6-7 \text { pontos }(\mathrm{p}<0,05) \\
\text { 8. redução }(\mathrm{p}<0,05) \\
\text { 9. aumento no espectro alfa }(\mathrm{p}<0,05) \\
\text { 10. aumento }(\mathrm{p}<0,05)\end{array}$ \\
\hline
\end{tabular}

Nota: (EC) Ensaio Clínico. 
QUADRO 1B - Descriçáo dos estudos (ensaios clínicos e estudo de caso) selecionados

\begin{tabular}{|c|c|c|c|c|c|c|}
\hline Estudo & $\begin{array}{l}\text { Desenho } \\
\text { Método- } \\
\text { lógico }\end{array}$ & Amostra & Desfechos Avaliados & $\begin{array}{l}\text { Instrumentos } \\
\text { de Avaliaçáo }\end{array}$ & $\begin{array}{l}\text { Análise } \\
\text { Estatística }\end{array}$ & $\begin{array}{c}\text { Efeitos Encontrados } \\
\text { (enumerados de acordo com os } \\
\text { desfechos avaliados) }\end{array}$ \\
\hline $\begin{array}{l}1999 \\
\text { Ohira Y } \\
\text { et al. }{ }^{8}\end{array}$ & ECRC & $\begin{array}{l}13 \text { adultos } \\
\text { saudáveis }\end{array}$ & $\begin{array}{l}\text { 1. modulação } \\
\text { mionuclear em fibras } \\
\text { de músculos esque- } \\
\text { léticos atrofiados em } \\
\text { humanos } \\
\text { 2. funçẫo da regulação } \\
\text { mionuclear } \\
\text { 3. modulação } \\
\text { mionuclear através da } \\
\text { atividade muscular }\end{array}$ & $\begin{array}{l}\text { Biópsia do } \\
\text { músculo sóleo } \\
\text { (perna esquerda) }\end{array}$ & $\begin{array}{l}\text { ANOVA } \\
\text { Scheffe's pos hoc } \\
\text { t-test }\end{array}$ & $\begin{array}{l}\text { 1. GC: a média do no de mionucléolos por mi- } \\
\text { límetros foi significativamente maior após } 1 \text { mês } \\
\text { de recuperação ambulatorial quando comparada } \\
\text { com } 2 \text { meses de repouso; O repouso não teve } \\
\text { efeito no no de mionucléolos por milímetros } \\
\text { para nenhum tipo de fibra. GPS: não havia } \\
\text { fibras específicas de atrofia no GPS1; a média do } \\
\text { tamanho das fibras ou foi mantido ou cresceu } \\
\text { após } 2 \text { meses de repouso quando comparadas } \\
\text { antes do repouso no GPS1 mas não no GPS2. } \\
\text { 2. GC: o número de mionucléolos por milíme- } \\
\text { tros nas cadeias pesadas de miosina tipo I (pu- } \\
\text { ras), após } 1 \text { mês de recuperação ambulatorial, } \\
\text { foi significativamente maior do que quando } \\
\text { comparadas com } 2 \text { ou } 4 \text { meses de repouso. GPS: } \\
\text { para fibras tipo I puro, a média da razáo do } \\
\text { volume citoplasmático/mionuclear cresceu após } \\
2 \text { meses de repouso quando comparadas antes } \\
\text { do repouso no GPS1; para fibras tipo I puro, } \\
\text { a média da razão do volume citoplasmático/ } \\
\text { mionuclear diminuiu após } 2 \text { meses de repouso } \\
\text { quando comparadas antes do repouso no GPS2. } \\
3 \text {. GC: houve aumento do número de mionu- } \\
\text { cléolos por milímetros em fibras tipo IIa após } \\
4 \text { meses de repouso quando comparadas com } 2 \\
\text { meses de repouso. }\end{array}$ \\
\hline
\end{tabular}

Nota: (ECRC) Ensaio Clínico Randomizado Controlado; (GC) Grupo Controle; (GPS) Grupo Pinguin Suit; (GPS1) Grupo Pinguin Suit 1; (GPS2) Grupo Pinguin Suit 2.

\begin{tabular}{|c|c|c|c|c|c|c|}
\hline \multicolumn{7}{|c|}{ QUADRO 1C - Descriçáo dos estudos (ensaios clínicos e estudo de caso) selecionados } \\
\hline Estudo & $\begin{array}{l}\text { Desenho } \\
\text { Método- } \\
\text { lógico }\end{array}$ & Amostra & $\begin{array}{l}\text { Desfechos } \\
\text { Avaliados }\end{array}$ & $\begin{array}{l}\text { Instrumentos } \\
\text { de Avaliaçáo }\end{array}$ & $\begin{array}{l}\text { Análise } \\
\text { Estatística }\end{array}$ & $\begin{array}{c}\text { Efeitos Encontrados } \\
\text { (enumerados de acordo com os desfechos } \\
\text { avaliados) }\end{array}$ \\
\hline $\begin{array}{l}2000 \\
\text { Ohira Y } \\
\text { et al. }{ }^{9}\end{array}$ & ECRC & $\begin{array}{l}13 \text { adultos } \\
\text { saudáveis }\end{array}$ & $\begin{array}{l}\text { 1. Biópsia do sóleo } \\
\text { 2. Análise histoquímica do } \\
\text { tipo de fibra muscular e da } \\
\text { cross sectional area } \\
\text { 3. Análise imunohistoquí- } \\
\text { mica da cadeia pesada de } \\
\text { miosina }\end{array}$ & $\begin{array}{l}\text { Biópsia do } \\
\text { músculo sóleo } \\
\text { (perna esquerda) }\end{array}$ & $\begin{array}{l}\text { Scheffe's pos } \\
\text { hoc } \\
\text { t-test }\end{array}$ & $\begin{array}{l}\text { 1. O percentual de fibras intermediárias cresceu } \\
\text { durante } 4 \text { meses de repouso no GC ( } \mathrm{p}<0,05 \text { ); } \\
\text { houve crescimento do percentual de distribui- } \\
\text { çáo das fibras intermediárias no GPS ( }<<0,05 \text { ) } \\
\text { nos } 2 \text { meses de repouso (não houve comparaçấo } \\
\text { intergrupos); } \\
\text { 2. A cross sectional área do GC reduziu durante } 2 \\
\text { e } 4 \text { meses de repouso ( }<<0,05 \text { ); foi significante- } \\
\text { mente menor quando com } 4 \text { meses do que com } \\
2 \text { meses ( }<0,05 \text { ); e após } 1 \text { mês de recuperação } \\
\text { foi significantemente maior do que com } 2 \text { e } 4 \\
\text { meses de repouso ( }<<0,05 \text { ); e no GPS2 (com a } \\
\text { roupa com elásticos, porém sem carga em plan- } \\
\text { tiflexores) reduziu durante } 2 \text { meses de repouso } \\
\text { ( }<0,05 \text { ) mas no GPS1 (com carga em plantifle- } \\
\text { xores) a atrofia foi prevenida; } \\
\text { 3. Penguin Suit (PS) é uma medida preventiva } \\
\text { para atrofia das fibras musculares; mas não são } \\
\text { uma medida preventiva para a transformação } \\
\text { das fibras musculares (de lentas para rápidas); }\end{array}$ \\
\hline
\end{tabular}

Nota: (ECRC) Ensaio Clínico Randomizado Controlado; (GC) Grupo Controle; (GPS) Grupo Pinguin Suit (GPS1) Grupo Pinguin Suit 1; (GPS2) Grupo Pinguin Suit 2. 


\begin{tabular}{|c|c|c|c|c|c|c|}
\hline \multicolumn{7}{|c|}{ QUADRO 1D - Descriçáo dos estudos (ensaios clínicos e estudo de caso) selecionados } \\
\hline Estudo & $\begin{array}{l}\text { Desenho } \\
\text { Métodoló- } \\
\text { gico }\end{array}$ & Amostra & Desfechos Avaliados & $\begin{array}{c}\text { Instrumentos } \\
\text { de } \\
\text { Avaliaçáo }\end{array}$ & $\begin{array}{l}\text { Análise } \\
\text { Estatística }\end{array}$ & $\begin{array}{c}\text { Efeitos Encontrados } \\
\text { (enumerados de acordo com os } \\
\text { desfechos avaliados) }\end{array}$ \\
\hline $\begin{array}{l}2001 \\
\text { Yamashita- } \\
\text {-Goto K } \\
\text { et al. }^{10}\end{array}$ & ECRC & $\begin{array}{l}13 \text { adultos } \\
\text { saudáveis }\end{array}$ & 1. Biópsia do sóleo & $\begin{array}{l}\text { Biópsia do } \\
\text { músculo sóleo } \\
\text { (perna esquerda) }\end{array}$ & $\begin{array}{l}\text { ANOVA } \\
\text { Scheffe's pos hoc } \\
\text { t-test }\end{array}$ & $\begin{array}{l}\text { 1. GC: maximum unloaded shortening } \\
\text { velocity foi significativamente maior } \\
\text { após } 2 \text { meses e } 4 \text { meses de repouso; a } \\
\text { força relativamente máxima pela área } \\
\text { cross sectional diminuiu significan- } \\
\text { temente após } 2 \text { meses e } 4 \text { meses de } \\
\text { repouso. GPS: o exercício resistido no } \\
\text { PS1 preveniu adaptaçôes de proprieda- } \\
\text { des contrateis (que ocorreram no GC) } \\
\text { após } 2 \text { meses de repouso; o alonga- } \\
\text { mento passivo do sóleo } 10 \text { h/dia com } \\
\text { os elásticos do PS, no GPS1 tiveram } \\
\text { efeito benéfico quando comparados } \\
\text { ao GPS2; a carga mecânica que alonga } \\
\text { o músculo, não necessariamente uma } \\
\text { contraçâo muscular é uma medida útil } \\
\text { para prevençâo do descondicionamento } \\
\text { em fibras lentas do sóleo. }\end{array}$ \\
\hline $\begin{array}{l}2006 \\
\text { Bar-Haim } \\
\text { S et al. }{ }^{4}\end{array}$ & $\begin{array}{l}\text { EC } \\
\text { Avaliaçóes } \\
\text { pré/pós- } \\
\text {-intevenção } \\
\text { (1 e } 9 \text { meses) }\end{array}$ & $\begin{array}{l}24 \text { crianças } \\
\text { di, tri e } \\
\text { quadriplégicas }\end{array}$ & $\begin{array}{l}\text { 1. estado funcional } \\
\text { 2. gasto metabólico - } \\
\text { subir escadas }\end{array}$ & $\begin{array}{l}\text { GMFM-66 } \\
\text { vídeos } \\
\text { monitoramento } \\
\text { da FC } \\
\text { (frequência } \\
\text { cardíaca) }\end{array}$ & Tukey's post hoc & $\begin{array}{l}\text { 1. melhora em ambos os grupos após } \\
1 \text { mês de tratamento; GB houve } \\
\text { melhora entre o baseline a após } 9 \text { meses } \\
\text { ( }<<0,006 \text { ); GAS houve melhora entre o } \\
\text { baseline a após } 1 \text { mês ( }<<0,037 \text { ); } \\
\text { 2. menor gasto energético após } 9 \text { meses } \\
\text { de tratamento para o GAS e com maior } \\
\text { GMFM66 ( }<<0,038 \text { ) em comparação } \\
\text { com o GB. } \\
\text { 3. } 1 \text { e } 2 \text {. Crianças do GAS com > } \\
\text { GMFM66 melhoraram seu gasto } \\
\text { energético em relação a crianças com } \\
<\text { GMFM66 ( }<0,04 \text { ). }\end{array}$ \\
\hline
\end{tabular}

Nota: (EC) Ensaio Clínico; (ECRC) Ensaio Clínico Randomizado Controlado; (GC) Grupo Controle; (GPS) Grupo Pinguin Suit; (OS) Pinguin Suit; (GPS1) Grupo Pinguin Suit 1; (GPS2) Grupo Pinguin Suit 2; (GAS) Grupo Adeli Suit; (GB) Grupo Bobath; (GMFM) Gross Motor Funcion Classification System.

\begin{tabular}{|c|c|c|c|c|c|c|}
\hline \multicolumn{7}{|c|}{ QUADRO 1E - Descriçáo dos estudos (ensaios clínicos e estudo de caso) selecionados } \\
\hline Estudo & $\begin{array}{c}\text { Desenho } \\
\text { Método- } \\
\text { lógico }\end{array}$ & Amostra & Desfechos Avaliados & $\begin{array}{c}\text { Instrumentos de } \\
\text { Avaliaçáo }\end{array}$ & $\begin{array}{c}\text { Análise } \\
\text { Estatística }\end{array}$ & $\begin{array}{c}\text { Efeitos Encontrados } \\
\text { (enumerados de acordo com os } \\
\text { desfechos avaliados) }\end{array}$ \\
\hline $\begin{array}{l}2010 \\
\text { Bailes } \\
\text { AF } \\
\text { et al. }{ }^{11}\end{array}$ & ECaso & $\begin{array}{l}2 \text { crianças } \\
\text { diplégicas }\end{array}$ & $\begin{array}{l}\text { 1. habilidades funcionais } \\
\text { 2. assistência do } \\
\text { cuidador } \\
\text { 3. habilidade motora } \\
\text { de pé } \\
\text { 4. habilidade motora } \\
\text { andando, correndo e } \\
\text { pulando } \\
\text { 5. marcha }\end{array}$ & $\begin{array}{l}\text { PEDI } \\
\text { GMFM (dimensóes } \\
\text { D e E) } \\
\text { Análise tridimensional } \\
\text { da marcha }\end{array}$ & $\begin{array}{l}\text { Não tem } \\
\text { (estudo de } \\
\text { caso) }\end{array}$ & $\begin{array}{l}\text { 1. mudanças mínimas e pequenas reduçôes } \\
\text { 2. mudanças mínimas e pequenas reduçóes } \\
\text { 3. mudanças mínimas } \\
\text { 4. mudanças mínimas } \\
\text { 5. mudanças nas características da } \\
\text { marcha em ambos os participantes }\end{array}$ \\
\hline
\end{tabular}

Nota: (ECaso) Estudo de Caso; (PEDI) Pediatric Evaluation of Disability Inventory; (GMFM) Gross Motor Funcion Classification System 
Quadro 2

Descriçâo das revisóes selecionadas

\begin{tabular}{|c|c|c|}
\hline Estudo & Objetivo(s) & Resultado(s) \\
\hline $\begin{array}{l}1990 \\
\text { Droppert } \mathrm{PM}^{5}\end{array}$ & Indeterminado & $\begin{array}{l}\text { O artigo fala de bases fisiológicas para o uso do exercício físico em } \\
\text { astronautas. } \\
\text { Fala de medidas preventivas para a perda de cálcio e descondicionamento } \\
\text { cardiovascular em ambientes sem gravidade como exercícios, dieta e } \\
\text { fármacos. } \\
\text { Relata que os cosmonautas russos utilizam a Penguin Suit durante o dia } \\
\text { e durante os exercícios para providenciar uma compensaçáo parcial da } \\
\text { ausência da gravidade quando no espaço e que a efetividade da suit ainda } \\
\text { não havia sito estabelecida. }\end{array}$ \\
\hline $\begin{array}{l}1995 \\
\text { Convertino CA } \\
\text { et al. }{ }^{6}\end{array}$ & $\begin{array}{l}\text { - presentar bases fisiológicas para o uso do } \\
\text { exercício físico em astronautas } \\
\text { - reforçar consideraçóes para o desenvolvimento de } \\
\text { medidas defensivas/preventivas; } \\
\text { - revisar exercícios durante o tempo no espaço, des- } \\
\text { crevendo os efeitos e as limitaçóes de suas aplicaçóes; } \\
\text { - providenciar novas abordagens e conceitos para a } \\
\text { implementação de exercícios no espaço. }\end{array}$ & $\begin{array}{l}\text { O artigo fala de bases fisiológicas para o uso do exercício físico em } \\
\text { astronautas. } \\
\text { Os autores falam de vários exercícios e recursos, e apenas citam o Penguin } \\
\text { Suit como uma vestimenta que os astronautas russos utilizavam durante } \\
\text { todo o dia, de } 8 \text { a } 12 \mathrm{~h} / \text { dia, inclusive realizando exercícios na esteira como } \\
\text { forma de produzir tensão na musculatura antigravitária. Ressalta que os } \\
\text { efeitos dessa suit na integridade musculoesquelética são desconhecidos. }\end{array}$ \\
\hline $\begin{array}{l}2003 \\
\text { Rosenbaum } P^{12}\end{array}$ & $\begin{array}{l}\text { Discutir brevemente porque pode ser difícil de } \\
\text { acertar um tratamento para crianças com PC - } \\
\text { convencional ou alternativo - e considerar quais } \\
\text { as regras devem ser aplicadas para julgar um novo } \\
\text { tratamento. }\end{array}$ & $\begin{array}{l}\text { O autor fala brevemente de várias técnicas, dentre elas o Adeli Suit, onde } \\
\text { menciona apenas que a técnica em si são exercícios controlados contra a } \\
\text { resistência (de fortalecimento). }\end{array}$ \\
\hline $\begin{array}{l}2005 \\
\text { Liptak GS }\end{array}$ & $\begin{array}{l}\text { Revisar } 9 \text { (nove) modalidades de terapias comple- } \\
\text { mentares e alternativas usadas em crianças PC. }\end{array}$ & $\begin{array}{l}\text { O autor menciona } 9 \text { técnicas, dentre elas o Adeli Suit, onde menciona que } \\
\text { a suit funciona como uma moldura elástica a redor do corpo, com elásti- } \\
\text { cos criando tensōes e teoricamente desenvolvendo músculos. Os benefícios } \\
\text { (teóricos) da técnica seriam: fortalecimento muscular, postura e coorde- } \\
\text { nação. Também é sentido pelo paciente pressáo profunda nas articulaçóes, } \\
\text { melhorando a informaçáo sensorial e proprioceptiva nas articulaçóes, } \\
\text { intensificando o input ao sistema vestibular e melhorando a coordenação. } \\
\text { Ressalta que não há evidência de um estudo clinico controlado em inglês, } \\
\text { nem a favor nem contra a técnica. }\end{array}$ \\
\hline
\end{tabular}

Nota: As revisões de literatura encontradas neste estudo são revisōes narrativas, abordando o tema de forma ampla e sem metodologia de seleção pré-estabelecida, semelhantes a capítulos de livros ${ }^{13}$.

\section{Características dos Participantes}

Três dos estudos analisados ${ }^{2,4,11}$ utilizaram uma amostra composta por crianças com diagnóstico de paralisia cerebral, classificados de acordo com a topografia e com o tipo de distúrbio do movimento. Um estudo ${ }^{2}$ analisou 60 crianças diplégicas espásticas e 34 diplégicas hipercinéticas, não mencionando a idade dos participantes. Outro $^{4}, 24$ crianças entre 6 e 12 anos, diplégicas espásticas e atáxicas, triplégicas espásticas e quadriplégicas espásticas e mistas. $\mathrm{O}$ estudo mais recente ${ }^{11}$, homogenizou a amostra em 2 crianças diplégicas espásticas, classificadas como nível III no GMFCS (Gross Motor Function Classification System). Quatro dos estudos foram realizados com adultos ${ }^{7-10}$. O primeiro estudo ${ }^{7}$ utilizou 55 pacientes adultos com lesão cerebrovascular aguda e com síndromes hipercinéticas, tendo os participantes idade acima de 24 anos. Os três últimos ${ }^{8-10}$, do mesmo grupo japonês e com a mesma amostragem, recrutou 13 homens saudáveis em seus ensaios clínicos controlados. As revisões ${ }^{3,12}$ envolveram crianças com paralisia cerebral; e os demais estudos $^{5,6}$ não mencionam a idade e a patologia.

O tamanho das amostras variou de 2 a 94 sujeitos (excetuando as revisões de literatura), divididos entre grupos tratamento e controle $e^{8-10}$, por patologias $s^{2,7,11}$ e por intervenção ${ }^{4}$.

\section{Características dos Programas de Intervenção}

O período de intervenção dos estudos analisados variou de $15^{9,11}$ a $60^{8-10}$ sessóes consecutivas, sendo que estas tiveram uma duração variável de $20 \operatorname{minutos}^{7}$ a 10 horas por $\mathrm{dia}^{8-10}$.

Todos os PIF utilizam a Universal Exercise Unit (UEU) ou "gaiola", uma estrutura de ferro onde ganchos são fixados a fim de se trabalhar o fortalecimento muscu- 
lar em movimentos isolados ou combinados. Os exercícios são realizados em suspensão - prono ou supino, podendo acoplar o sistema de roldanas para trabalhos com resistência ou o Spider, um sistema dinâmico de cordas elásticas que estabiliza, facilita e fortalece a musculatura ${ }^{11}$. O fisioterapeuta pode dificultar ou facilitar a função, modificando o sistema de cordas. Na UEU pode-se trabalhar com ou sem a roupa com elásticos, utilizando-se de várias e diferentes técnicas fisioterapêuticas.

O protocolo terapêutico também foi diversificado: em dois estudos ${ }^{2,7}$ a roupa com elásticos foi utilizada para deambulação e em quatro estudos ${ }^{4,8-10}$ para exercícios diversos. Apenas um estudo ${ }^{11}$ utilizou ambos - deambulação e exercícios (Quadro 3).

Dois estudos ${ }^{4,11}$ utilizaram o PIF associado à roupa com elásticos. O ensaio clínico randomizado ${ }^{4}$, comparou o AdeliSuit Therapy (AST) e o Método Bobath em 24 crianças com paralisia cerebral. Os resultados estatisticamente significativos foram uma melhora no gasto energético após 9 meses de tratamento para o grupo AST com maior GMFM66 em comparação com o grupo Bobath; houve melhora em ambos os grupos após 1 mês de tratamento. No entanto, o grupo AST não demonstrou retenção de habilidades motoras superior ao grupo Bobath. Os autores concluem que o PIF associado à roupa com elásticos objetiva a melhora de habilidades motoras em crianças com maiores níveis no GMFM66, refletindo em uma redução do gasto metabólico. Acreditam que pode haver uma aceleração do processo de aquisição destas habilidades em crianças com paralisia cerebral. No entanto, este estudo compara diferentes princípios: um recurso, a roupa com elásticos e um método, Bobath.

$\mathrm{O}$ estudo de caso ${ }^{11}$ investigou os efeitos do PIF utilizando a roupa com elásticos na marcha, nas tarefas motoras, na habilidade motora grossa e na assistência dos cuidadores. Nas dimensões D e E do GMFM e no PEDI, houveram ganhos considerados pelos autores como mínimos, e diminuição em algumas áreas de performance funcional. $\mathrm{Na}$ análise da marcha, notaram modificaçóes nos parâmetros cinemáticos como aumento da velocidade, melhora da extensão do quadril na fase de apoio terminal, melhora da simetria corporal na rotação pélvica e redução da hiperextensão do joelho no apoio médio.
Efeitos da roupa com elásticos e do PIF nas características neuromusculares e musculoesqueléticas mais comumente descritos

As revisóes encontradas neste estudo demonstram que os efeitos na integridade musculoesquelética ainda são desconhecidos ${ }^{5,6}$. As revisões ${ }^{3,12}$ mostram a inesistência de estudos na língua inglesa sobre a roupa com elásticos, não havendo evidência que justifique ou não sua utilização. Já os 3 ensaios clínicos randomizados e controlados do grupo japonês ${ }^{8-10}$ demonstram que a roupa com elásticos é uma medida preventiva para atrofia de fibras musculares do músculo estudado por eles, o sóleo. O estudo russo ${ }^{7}$ mensurou a força muscular e a espasticidade em seus participantes, mas não descreveu os instrumentos utilizados e os valores encontrados, dificultando sua análise. $\mathrm{O}$ autor conclui, no entanto, haver melhora da força muscular no hemicorpo acometido e redução da espasticidade.

O estudo mais recente ${ }^{11}$ reforça que mesmo havendo indicaçóes de uma tendência na melhora da função após o PIF utilizando a roupa com elásticos, a efetividade de ambos na marcha e na função ainda não foi estabelecida. Do mesmo modo, a intensidade apropriada dos exercícios e do alongamento, necessária para maximizar os benefícios, continua desconhecida. Este estudo traz relatos de que na prática clínica, as famílias informaram não ter havido mudanças funcionais observáveis de imediato ao término de uma intervenção, somente após um tempo. Sugerindo, portanto, a necessidade de um acompanhamento a longo prazo a fim de se avaliar o aprendizado motor e a retenção dos participantes.

\section{DISCUSSÃO}

Há uma heterogenicidade nas amostras dos estudos revisados, dificultando uma análise de acordo com a idade, o tempo de lesão e a gravidade dos comprometimentos neurológicos. Os estudos utilizados nesta revisão são, excetuando as revisões narrativas, primários, e, portanto, diferentes em relação ao perfil do participante, tipo de intervenção realizada e a definição do desfecho.

O PIF, incluindo a roupa com elásticos é um recurso de reabilitação utilizada em pacientes neurológicos, com o objetivo de prover melhora funcional, manuten- 
ção e/ou redução de déficits motores. O programa foca o desenvolvimento motor, o fortalecimento muscular, a resistência, a flexibilidade, a coordenação motora e o equilíbrio. O PIF se baseia em três princípios: 1) o efeito da roupa, gerando carga/tensão resistiva aplicada à musculatura (fortalecimento muscular), aumentando a pro-

Quadro 3

Características dos programas de intervenção

\begin{tabular}{|c|c|c|}
\hline Estudo & $\begin{array}{l}\text { Período de Intervençãa/ } \\
\text { Duraçáo da Sessão }\end{array}$ & Protocolo terapêutico utilizado/Intervençáo \\
\hline $\begin{array}{c}1997 \\
\text { Semenova } \\
\mathrm{KA}^{2}\end{array}$ & - $30-40$ mins & Deambulação realizando os movimentos que quisessem. \\
\hline $\begin{array}{l}1997 \\
\text { Shvarkov } \\
\text { SB et al }\end{array}$ & $\begin{array}{l}\text { Diário - } 15 \text { dias consecutivos; } \\
20 \text { a } 120 \text { mins }\end{array}$ & $\begin{array}{l}\text { Métodos tradicionais de reabilitaçáo (nấo especifica quais) foram suplementados } \\
\text { com o uso do Adeli Suit: marcha, deambulaçãa lateral, deambulação em linha, } \\
\text { desvios laterais, subir e descer escadas, seguir caminhos em forma de S. }\end{array}$ \\
\hline $\begin{array}{l}1999 \\
\text { Ohira Y, } \\
\text { et al. }\end{array}$ & $\begin{array}{l}\text { Diário } \\
150 \text { mins realizando exercícios } \\
\text { com a vestimenta; } \\
600 \text { mins utilizando a } \\
\text { vestimenta }\end{array}$ & 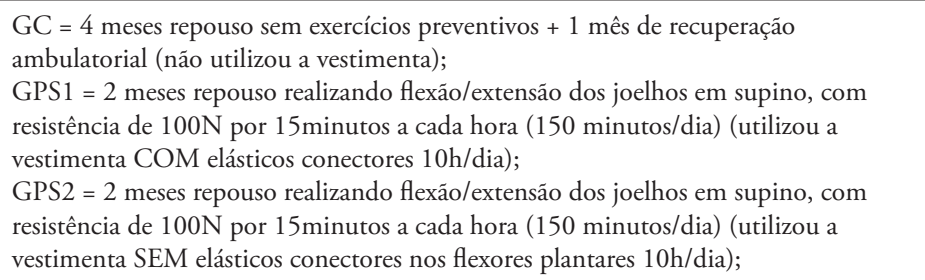 \\
\hline $\begin{array}{l}2000 \\
\text { Ohira Y, } \\
\text { et al. }{ }^{9}\end{array}$ & $\begin{array}{l}\text { Diário } \\
150 \text { mins realizando exercícios } \\
\text { com a vestimenta; } \\
600 \text { mins utilizando a } \\
\text { vestimenta }\end{array}$ & $\begin{array}{l}\text { GC = } 4 \text { meses repouso sem exercícios preventivos + } 1 \text { mês de recuperação } \\
\text { ambulatorial (não utilizou a vestimenta); } \\
\text { GPS } 1=2 \text { meses repouso realizando flexão/extensão dos joelhos em supino, com } \\
\text { resistência de } 100 \mathrm{~N} \text { por } 15 \text { minutos a cada hora ( } 150 \text { minutos/dia) (utilizou a vesti- } \\
\text { menta COM elásticos conectores } 10 \mathrm{~h} / \text { dia); } \\
\text { GPS } 2 \text { = } 2 \text { meses repouso realizando flexão/extensão dos joelhos em supino, com } \\
\text { resistência de } 100 \mathrm{~N} \text { por } 15 \text { minutos a cada hora }(150 \text { minutos/dia) (utilizou a vesti- } \\
\text { menta SEM elásticos conectores nos flexores plantares } 10 \mathrm{~h} / \mathrm{dia}) ;\end{array}$ \\
\hline $\begin{array}{l}2001 \\
\text { Yamashita-Goto } \\
\mathrm{K}, \text { et al. }{ }^{10}\end{array}$ & $\begin{array}{l}\text { Diário } \\
\text { Utilizaram a suit } 10 \mathrm{~h} / \mathrm{dia} \\
\text { Exercícios com a suit } 2.5 \mathrm{~h} / \mathrm{dia}\end{array}$ & $\begin{array}{l}\text { GC = } 4 \text { meses repouso sem exercícios preventivos + } 1 \text { mês de recuperaçáo } \\
\text { ambulatorial (não utilizou a suit); } \\
\text { GPS1 = } 2 \text { meses repouso usando a suit } 10 \mathrm{~h} / \text { dia e realizando flexão/extensão dos } \\
\text { joelhos em supino, com uma resistência de } 100 \mathrm{~N} \text { por } 15^{\prime} \text { a cada hora }(2.5 \mathrm{~h} / \mathrm{dia}) \\
\text { GPS } 2 \text { = } 2 \text { meses repouso usando a suit } \mathrm{SEM} \text { os elásticos conectores e tensores nos } \\
\text { flexores plantares } 10 \mathrm{~h} / \text { dia e realizando flexão/extensão dos joelhos em supino, com } \\
\text { uma resistência de } 100 \mathrm{~N} \text { por } 15^{\prime} \text { a cada hora }(2.5 \mathrm{~h} / \mathrm{dia}) \text {. }\end{array}$ \\
\hline $\begin{array}{l}2006 \\
\text { Bar-Haim S, } \\
\quad \text { et al. }\end{array}$ & $\begin{array}{l}20 \text { sessóes: } \\
5 \text { dias/semana } \\
4 \text { semanas consecutivas } \\
120 \text { mins }\end{array}$ & $\begin{array}{l}\text { GAS = massagem, alongamento passivo grupos musculares de MMSS e MMII, } \\
\text { vestimenta (alinhamento corporal e restringindo posiçōes de membros), exercícios } \\
\text { rigorosos com a vestimenta (não especifica). } \\
\text { GB = não tem protocolo específico. }\end{array}$ \\
\hline $\begin{array}{c}2010 \\
\text { Bailes AF, et al. }{ }^{11}\end{array}$ & $\begin{array}{l}15 \text { sessôes: } \\
5 \text { dias/semana } \\
3 \text { semanas consecutivas } \\
240 \text { mins }\end{array}$ & $\begin{array}{l}30 \text { mins: Termoterapia e massagem (bolsas quentes durante } 12-15 \text { mins; } 3-6 \text { mins } \\
\text { massagem em cada membro inferior; } 3 \text { mins massagem em cada membro superior); } \\
30-45 \text { mins: Pulleys (aproximadamente } 2-4 \text { exercícios com } 30 \text { repetiçóes cada, } \\
\text { usando a Universal Exercise Unit para alongamento e fortalecimento de MMII); } \\
\text { 5-10mins: descanso; } \\
\text { 15-20 mins: colocação da vestimenta com cordas elásticas; } \\
30-40 \text { mins: exercícios terapêuticos ( } 3-6 \text { exercícios com } 30 \text { repetiçóes cada para forta- } \\
\text { lecimento e alongamento de tronco e de MMII, utilizando a bola Suíça, banquinhos } \\
\text { e outros); } \\
5 \text { mins: descanso; } \\
20 \text { mins: Pulleys (aproximadamente } 2 \text { exercícios com } 30 \text { repetiçôes cada, usando a } \\
\text { Universal Exercise Unit para alongamento e fortalecimento de MMSS); } \\
5 \text { mins: atividades sensório-motoras (utilizando a Universal Exercise Unit para saltos } \\
\text { ou balanços); } \\
30 \text { mins: atividades de vida diária e progressão de tarefas de habilidades motoras } \\
\text { finas; } \\
5 \text { mins: descanso; } \\
20-30 \text { mins: atividades de balance e coordenação (1-3 exercícios utilizando a } \\
\text { Universal Exercise Unit); } \\
20-30 \text { mins: ficando de pé, transiçôes porturais e progressão de habilidades para a } \\
\text { marcha. }\end{array}$ \\
\hline
\end{tabular}

Nota: (GC) Grupo Controle; (GPS1) Grupo Pinguin Suit 1; (GPS2) Grupo Pinguin Suit 2; (GAS) Grupo Adeli Suit; (mins) minutos; (MMII) membros inferiores; (MMSS) membros superiores; (GB) Grupo Bobath, (suit) vestimenta com cordas elásticas. 
priocepção e o realinhamento biomecânico; 2) o treino fisioterápico intensivo em habilidades motoras (exercícios com duração prolongada e sessões diárias durante um período de algumas semanas) ${ }^{14}$ e 3) a participação motora ativa do paciente.

Realizado em 3 ou 4 semanas consecutivas, esta abordagem terapêutica exige do paciente e de seus familiares dedicação e tempo. A duração das sessões é de 3 a 6 horas diárias e sua frequência, de 5 a 6 dias por sema$\mathrm{na}^{4,11}$, variando de acordo com o "protocolo": Adeli Method, TheraSuit Method, PediaSuit Method ou NeuroSuit Method. Além do PIF e da roupa com elásticos, alguns incluem a hipoterapia, a hidroterapia, o alongamento, a liberação miofascial, o aquecimento com massagens, a termoterapia e cinesioterapia específica.

Considerando os diversos programas de intervenção, percebe-se que não há "regras" para o recurso de reabilitação em questão, nem um "protocolo" a ser seguido. Portanto, não pode ser considerada uma técnica, variando a cada fisioterapeuta e a cada "patente" a conduta adotada, impossibilitando uma comparação entre os programas de intervenção encontrados.

A teoria que envolve a roupa com elásticos é a indução de fortes aferências proprioceptivas que estimulam a formação de novas vias encefálicas ${ }^{2,7}$. Esta aferência emerge do sistema de elásticos da roupa que atua como um "exo-esqueleto", contribuindo para a habilidade do paciente em formar novas programaçóes motoras através do realinhamento postural. Dentro deste paradigma, a reeducação da postura e da função muscular permite ao paciente aprender ou reaprender padróes adequados de movimento ${ }^{15}$.

A correção simultânea de açóes aferentes do sistema vestibuloproprioceptivo envia informaçóes a estruturas centrais de análise do movimento de todas as partes dos sistemas muscular e articular envolvidos nas funçóes anti-gravitárias ${ }^{2}$. Assim, há uma restauração das sinergias musculares fisiológicas através da carga/tensão aplicada pelos elásticos. O efeito da carga/tensão é reportado na literatura como um regulador da síntese e degradação de proteínas em músculos esqueléticos ${ }^{10}$. $\mathrm{O}$ aumento desta carga/tensão que ocorre com o exercício físico e com o alongamento, estimula a síntese de proteínas e frequentemente resulta em hipertrofia. A diminuição desta car- ga/tensão resulta em perda de proteínas musculares e/ou atrofia, especialmente em músculos anti-gravitários ${ }^{2,10}$.

Assim, não havendo clareza no modo como a roupa com elásticos influencia a excitabilidade do alfa-motoneurônio, há a necessidade de mais especulação. Faz-se necessário comparar o PIF associado à roupa com elásticos com o programa em si, assim como verificar a eficácia da roupa com elásticos, mensurando força muscular, tônus muscular, amplitude de movimento, controle motor, realinhamento postural e fadiga em uma amostra homogênea. É importante também investigar as alteraçôes fisiológicas geradas por estes recursos como a pressão arterial, a frequência cardíaca e o gasto metabólico (diante de um mesmo intake calórico) - o que possivelmente nos fará compreender os mecanismos de ação da roupa com elásticos. Vale salientar que a utilização de instrumentos objetivos como a eletroneuromiografia, a mensuração da tensão dos elásticos e a ressonância magnética funcional, investigando possíveis alteraçóes na plasticidade cerebral, seria de grande valia para a comprovação da eficácia dos recursos abordados.

Cabe avaliar se a roupa com elásticos age causando uma mudança no input aferente em determinados músculos. Se isso acontece, a excitabilidade do alfa-motoneurônio é afetada, podendo ser mensurada pela mudança da amplitude do reflexo espinal. Se esta amplitude for reduzida com a roupa com elásticos haveria uma redução da excitabilidade do alfa-motoneurônio, ou seja, uma inibição. Em contra partida, se a amplitude do reflexo aumentar, haveria uma facilitação desta excitabilidade ${ }^{16}$.

Outro aspecto a considerar é a mensuração da tração do elástico. São vários elásticos, de tamanhos diferentes que oferecem trações diferentes e são utilizados para inibir ou facilitar determinados músculos, conforme a sua posição e o sentido de colocação.

Deste modo, seriam necessários estudos sobre o mesmo músculo e sobre os músculos que recebem a mesma inervação, para comprovar ou refutar a teoria acima, utilizando a roupa com elásticos. Será que os músculos responderiam da mesma forma? Seria uma regra independente do músculo, mas dependente da direção em que o elástico é tracionado? Como este reflexo (inibido ou facilitado) reagiria se comparado antes, durante, imediatamente após e alguns dias após o uso da roupa com elásticos? 
Dos 11 estudos desta revisão, 4 foram conduzidos há mais de 14 anos e a aplicabilidade de seus resultados na prática clínica podem ser comprometidos devido às mudanças nas características da população, das intervençôes médicas e das técnicas fisioterapêuticas nas patologias em questão.

\section{CONCLUSÃO}

O PIF associado ao uso da roupa com elásticos mostrou-se, portanto, um recurso promissor que ainda necessita de investigaçôes, não sendo possível determinar se ele produz ou não desfechos benéficos para indivíduos com déficits neurológicos.

Os resultados desta revisão sistemática de literatura sugerem que explicaçóes sobre os mecanismos envolvidos, do PIF, da roupa com elásticos e sobre a associação de ambos, precisam ser estudados em pacientes neurológicos, a fim de apontar caminhos para que tais recursos terapêuticos sejam refutados ou utilizados com segurança.

Futuras investigaçóes poderão esclarecer algumas inconsistências observadas nos resultados dos estudos, provavelmente devido à heterogeneidade metodológica, às diferenças nos tipos de "protocolos" adotados, às características dos participantes e os instrumentos de avaliação, favorecendo a prática baseada em evidências.

\section{REFERÊNCIAS}

1.Schumway-Cook A, Woollacott MH. Controle Motor: teoria e aplicaçôes práticas. Barueri: Manole, 2003, 592p.

2.Semenova KA. Basis for a method of dynamic proprioceptive correction in the restorative treatment of patients with residual-stage infantile cerebral palsy. Neurosci Behav Physiol 1997;27:639-43.

http://dx.doi.org/10.1007/BF02461920

3.Liptak GS. Complementary and alternative therapies for cerebral palsy.
Ment Retard and Dev D R 2005;11:156-63.

http://dx.doi.org/10.1002/mrdd.20066

4.Bar-Haim S, Harries N, Belokopytov M, Frank C, Copeliovitch, L, Kaplanski $\mathrm{J}$, et al. Comparison of efficacy of Adeli Suit and neurodevelopmental treatments in children with cerebral palsy. Dev Med Child Neurol 2006;48:325-30. http://dx.doi.org/10.1017/S0012162206000727

5.Droppert PM. The effects of microgravity on the skeletal system - a review. JBIS 1990;43:19-24.

6.Convertino CA, Sandler H. Exercises countermeasures for spaceflight. Acta Astronaut 1995;35:253-70.

http://dx.doi.org/10.1016/0094-5765(95)98731-N

7.Shvarkov SB, Davydov OS, Kuuz RA, Aipova TR, Vein AM. New approaches to the rehabilitation of patients with neurological movement defects. Neurosci Behav Physiol 1997;27:644-47.

http://dx.doi.org/10.1007/BF02461921

8. Ohira Y, Yoshinaga T, Ohara M, Nonaka I, Yoshioka T, Yamashita-Goto K, et al. Myonuclear domain and myosin phenotype in human soleus after bed rest with or without loading. J Appl Physiol 1999;87:1776-85.

9.Ohira Y, Yoshinaga T, Ohara M, Nonaka I, Yoshioka T, Yamashita-Goto K, et al. Histochemical Responses of Human Soleus Muscle Fiber after long-term bedrest with or without countermeasures. JPN J Physiol 2000;50:41-47.

http://dx.doi.org/10.2170/ijphysiol.50.41

10.Yamashita-Goto K, Okuyama R, Honda M, Kawasaki F, Fuijita K, Yamada $\mathrm{T}$, et al. Maximal and submaximal forces of slow fibers in human soleus after bed rest. J Appl Physiol 2001;91:417-24.

11.Bailes AF, Greve K, Schmitt LC. Changes in two children with cerebral palsy after intensive suit therapy: a case report. Pediatr Phys Ther 2010;22:76-85. http://dx.doi.org/10.1097/PEP.0b013e3181cbf224

12.Rosenbaum P. Controversial treatment for spasticiy: exploring alternatives therapies for motor function in children with cerebral palsy. J Child Neurol 2003;18:S89-S94.

13.Berwanger O, Suzumura EA, Buehler AM, Oliveira JB. Como avaliar criticamente revisôes sistemáticas e metanálises? Rev Bras Ter Intensiva 2007;19:475-80.

http://dx.doi.org/10.1590/S0103-507X2007000400012

14.Ödman P, Öberg B. Effectiveness of Intensive Training for children with cerebral palsy - a comparison between child and youth rehabilitation and conductive education. J Rehabil Med 2005;37:263-70.

http://dx.doi.org/10.1080/16501970510032622

15.Fanagan A, Krzak J, Peer M, Johnson P, Urban M. Evaluation of Short-term Intensive orthotic garment use in children who have cerebral palsy. Pediatr Phys Ther 2009;21:201-04.

http://dx.doi.org/10.1097/PEP.0b013e3181a347ab

16.Alexander CM, McMullan M, Harrison PJ. What is the effect of taping along or across a muscle on motoneurone excitability? A study using triceps surae. Manual Ther 2008;13:57-62.

http://dx.doi.org/10.1016/j.math.2006.08.003 